\title{
Case of IgG4 orbitopathy's remarkable response to oral corticosteroid therapy
}

\author{
Neelima Balakrishnan, Rachna Meel, Deepsekhar Das
}

Dr RP Centre for Ophthalmic Sciences, All India Institute of Medical Sciences, New Delhi, India

\section{Correspondence to Dr Deepsekhar Das; doc.deep.das@gmail.com}

Accepted 25 July 2020

Check for updates

(c) BMJ Publishing Group Limited 2020. No commercial re-use. See rights and permissions. Published by BMJ.

To cite: Balakrishnan N, Meel R, Das D. BMJ Case Rep 2020;13:e236442. doi:10.1136/bcr-2020236442

\section{DESCRIPTION}

A 45-year-old man presented to the outpatient department with symptoms of outward protrusion of both eyes for the past 20 years (figure 1). The swelling was gradually progressive in nature, painless and more on the right side. It was associated with redness and watering. There was no history of thyroid related problems or any other systemic disease.

On general examination he was of good built and systemic examination was within normal limits. On ocular examination there was bilateral proptosis, measured as $29 \mathrm{~mm}$ and $24 \mathrm{~mm}$ with Hertel's exophthalmometry in the right and left eye, respectively at base 116. There was diffuse swelling of upper and lower lids in both eyes along with conjunctival prolapse. There were firm palpable lesions in the superotemporal aspect of both orbit. Retropulsion test was negative. Visual acuity was 6/6 in the snellens chart. Anterior segment and posterior segments were within normal limits.

Patient underwent routine blood investigations which came out to be normal, thyroid function test was also normal. Contrast Enhanced Magnetic Resonance Imaging (CEMRI) of head and orbit revealed proptosis of both globes. T1, T2 and Fluid-attenuated inversion recovery (FLAIR) showing isointense lesions with uniform enhancement in extraconal spaces anteriorly, laterally and superiorly (figure 2). There was infiltration in bilateral eyelids, superior oblique, superior rectus and lateral rectus muscles were displaced inferiorly and medially in both the eyes.

The patient underwent biopsy on H\&E staining revealed plasma lymphocytic infiltration and on immunostaining for IgG4 showed multiple IgG4 positive plasma cells (figure 3 ).

A diagnosis of $\operatorname{IgG} 4$ orbitopathy was made and he was investigated for systemic involvement. X-ray chest revealed cardiomegaly, Contrast Enhanced Computed Tomography (CECT) chest revealed peri hilar lymphadenopathy. A gallium 68 dotatate whole body positron emission tomography was performed (68 Ga DOTANOC PET) which showed somatostatin receptor expression in bilateral lacrimal glands, bilateral superior and lateral recti muscles. He was started on oral corticosteroids $1 \mathrm{mg} / \mathrm{kg}$ dose and tapered over the period of 8 weeks. There was a remarkable response to treatment (figure 4). The 68 Ga DOTANOC whole body PET scan showed reduction in uptake.

IgG4-related disease (IgG4-RD) is an immune mediated, multiorgan, protean condition with multiple manifestations. It is primarily an immune disorder, wherein infiltration with IgG4-positive plasma cells affects multiple organ systems in the human body characterised by lymphoplasmacytic infiltration, storiform fibrosis, obliterative phlebitis and mild to moderate eosinophilia.

The entity was first reported in 2003, as a distinct clinicopathological condition with multiple manifestations in patients with autoimmune pancreatitis in Japan. ${ }^{1}$ These patients were found to have extensive IgG4-positive plasma cell infiltration of organs along with CD4 or CD8 positive T lymphocytes in the portal area of the liver, the colon, stomach, salivary glands, lymph nodes and bone marrow. Overall prevalence of IgG4-related autoimmune pancreatitis in Japan has been estimated to be 2.2 cases per 100000 population, ${ }^{2}$ but the relative prevalence of various organ manifestations remains unclear as of now. Most common manifestations include autoimmune pancreatitis, sialadenitis, dacryoadenitis and retroperitoneal fibrosis. ${ }^{3}$ The disease has been described in virtually every organ system. The majority of patient $(62 \%-83 \%)$ are seen to be middle-aged men (more than 50 years old), in contrast to the usual pattern seen in autoimmune diseases which show female preponderance. ${ }^{4}$ However, when organs of head and neck are involved, including orbit, salivary glands and paranasal sinuses, similar pattern of involvement has been observed in both genders. ${ }^{5}$

The comprehensive diagnostic criteria for IgG4 related disease was established in 2011 by two study groups, the Umehara and Okazaki teams, organised by The Ministry of Health, Labour and Welfare of Japan. ${ }^{6}$

The disease onset is typically subacute in nature. Features of organ dysfunction may be evident for years before a definitive diagnosis is made. Few cases present with fever and constitutional symptoms while fatigue and musculoskeletal manifestations are more commonly observed. The disease may show occasional temporary improvement and long quiescent phases. Many patients may have associated atopic conditions such as eczema or asthma. ${ }^{7}$ The disease is also associated with multiple tumorous swellings in various organ systems and patients may present with mass lesions, not associated with pain. Non-tender generalised or localised lymphadenopathy in the draining region of the affected organ may be observed. Vascular involvement is seen in the form of IgG4 related periarteritis/periaortitis causing vessel wall thickening. Liver involvement may lead to cholangitis while tubulointerstitial nephritis has been reported as a manifestation in kidney involvement. 


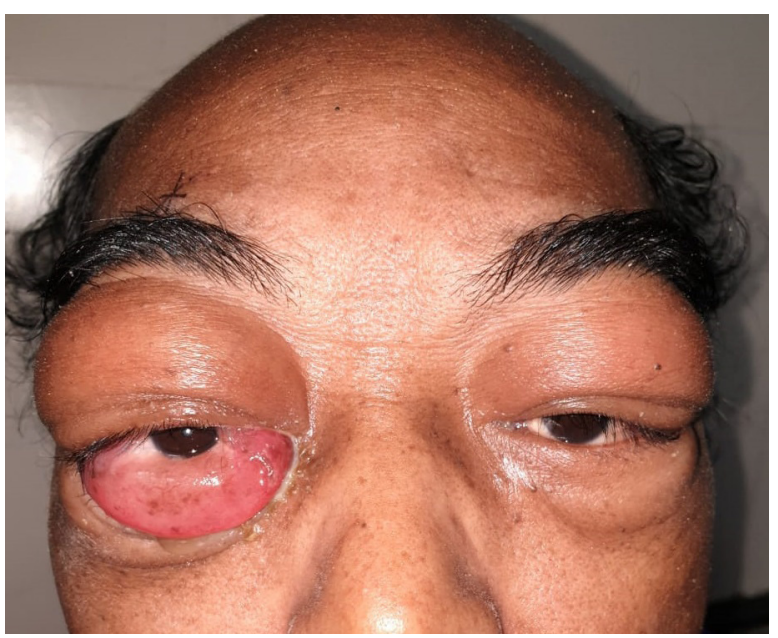

Figure 1 Clinical picture of the patient showing bilateral proptosis with conjunctival prolapse in the right side.

Salivary gland involvement presents in the form of Mikulicz's disease, characterised by enlargement of submandibular and parotid glands along with dacryoadenitis and xerostomia, which responds well to immunosuppression. ${ }^{8}$ Thyroid involvement presents in the form of Reidel's thyroiditis. Indurated nodules in skin and soft tissue of head and neck region was observed in less than $1 \%$ of cases. ${ }^{9}$

Orbital manifestations are seen in more than half of the patients of IgG4 related disease with head and neck involvement. ${ }^{9}$ In patients with IgG4 related orbitopathy, bilateral lacrimal gland involvement is typical. ${ }^{10} 25 \%-50 \%$ of orbital pseudotumours may be attributed to IgG4-RD. ${ }^{11}$ It has been described as one of the sclerosing lesions of the orbit. ${ }^{12}$ Presenting features of proptosis and diplopia are also seen possibly due to orbital myositis. Swelling of eyelids and lacrimal glands may point towards possible dacryoadenitis. Bilateral orbital involvement

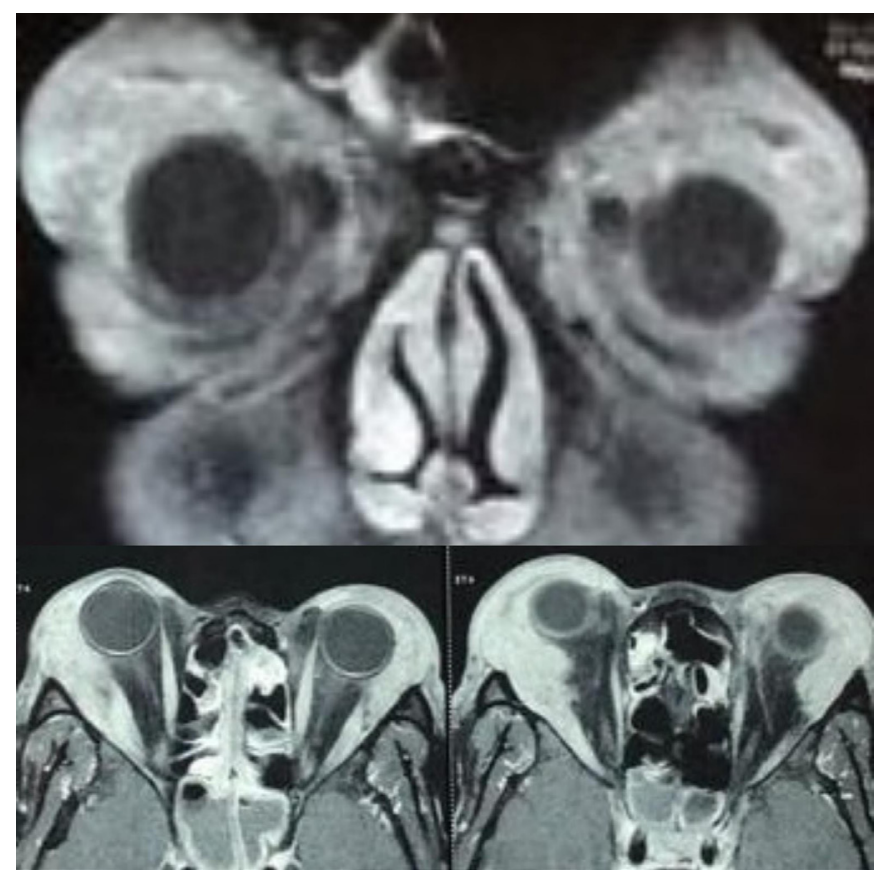

Figure 2 Contrast Enhanced Magnetic Resonance Imaging (CEMRI) T1-weighted images of head and orbit showing in enhancing lesion in the superotemporal aspect of both orbits.

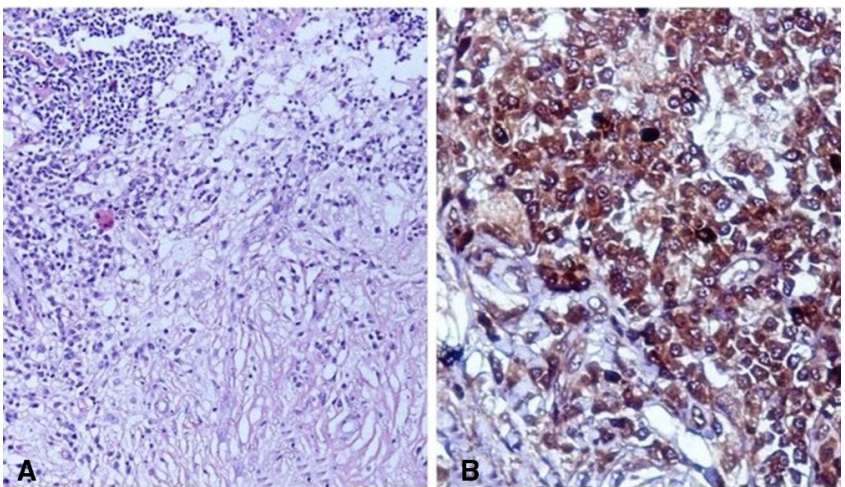

Figure 3 Histopathology slides showing (A) plasma lymphocytic infiltration on H\&E stain. (B) Immunostaining showing IgG4 positive plasma cells.

was seen in $50 \%$ or more of previously reported cases. ${ }^{13}$ Supraorbital or infraorbital nerve involvement may present with sensory impairment. Optic nerve involvement may lead to visual impairment. $^{9}$

Diagnostic modalities include imaging to demonstrate enlargement of the affected organ, laboratory investigations showing elevated IgG4 levels as well as characteristic features demonstrated in histopathological sections. ${ }^{6}$ Around $30 \%$ of patients of IgG4-RD may not demonstrate elevated IgG4 levels in blood. ${ }^{14}$ Serum complement levels are also a useful indicator of disease activity, particularly when renal involvement is suspected.

Imaging modalities are useful to differentiate the lesions from malignancies. Ultrasound may be used as an initial imaging modality in IgG4-RD of head and neck particularly when thyroid and salivary gland involvement is suspected. It would also facilitate tissue sampling. ${ }^{15}$ CT or MRI may be useful for imaging of mass lesions. Bony involvement has been shown to be better documented with CT scans while infiltrative lesions may be better assessed with MRI. PET scanning may help in picking up asymptomatic disease and monitoring response to treatment. ${ }^{15}$

Gold standard in IgG4 diagnosis is histopathological examination of tissue specimens. Typical features of mild to moderate eosinophilia, dense plasma lymphocytic infiltrate and obliterative phlebitis may be seen. The infiltrate may be arranged in matted and whorled pattern, typically described as 'storiform'. ${ }^{16}$

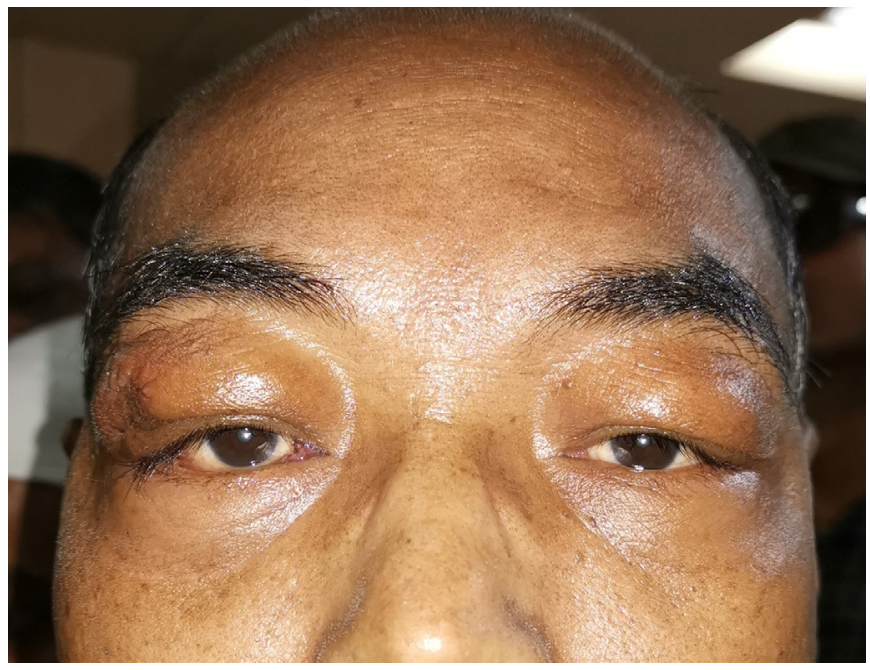

Figure 4 Clinical picture of patient showing significant reduction of proptosis. 
Presence of IgG4 plasma cell infiltrates in the specimen may also be seen in malignancies as well as in other conditions such as Wegener's granulomatosis or Churg-Strauss disease. Formation of reactive lymphoid follicles may also be seen.

Management involves initiation of therapy with glucocorticoids. When associated with life threatening systemic manifestations, urgent treatment must be initiated. Prednisolone may be started at a dose of $0.6-1.0 \mathrm{mg} / \mathrm{kg}$ daily and continued for a period of 2-4 weeks. Response to treatment can be assessed by evaluation of IgG4 levels, follow-up imaging studies and clinical correlation and further doses may be tapered accordingly. For long term maintenance therapy, steroid sparing agents such as azathioprine may be tried. In cases not responding to steroids, rituximab may be useful.

In our case the patient responded very well with oral prednisolone and there has been no recurrence in the past 3 months.

\section{Patient's perspective}

My eyes have been swollen for a very long duration. I am happy that it finally reduced but I am scared as my doctors are saying it may come back after I stop medicines.

\section{Learning points}

IgG4 orbitopathy can present in various ways. A thorough systemic evaluation is important to rule out associated systemic conditions.

- The disease usually shows a good response to oral corticosteroid therapy.

Contributors RM and DD participated in diagnosis and treatment of the patient. NB and DD participated in preparing the manuscript and finalising it under RM guidance.

Funding The authors have not declared a specific grant for this research from any funding agency in the public, commercial or not-for-profit sectors.
Competing interests None declared.

Patient consent for publication Obtained.

Provenance and peer review Not commissioned; externally peer reviewed.

\section{ORCID iD}

Deepsekhar Das http://orcid.org/0000-0002-4446-0274

\section{REFERENCES}

1 Kamisawa T, Funata N, Hayashi Y, et al. A new clinicopathological entity of IgG4related autoimmune disease. J Gastroenterol 2003;38:982-4.

2 Kanno A, Masamune A, Okazaki K, et al. Nationwide epidemiological survey of autoimmune pancreatitis in Japan in 2011. Pancreas 2015;44:535-9.

3 Stone JH, Chan JKC, Deshpande V, et al. Igg4-Related disease. Int J Rheumatol 2013;2013:1-2.

4 Frulloni L, Lunardi C, Simone R, et al. Identification of a novel antibody associated with autoimmune pancreatitis. N Engl J Med 2009;361:2135-42.

5 Zen Y, Nakanuma Y. Igg4-Related disease: a cross-sectional study of 114 cases. Am J Surg Pathol 2010;34:1812-9.

6 Umehara H, Okazaki K, Masaki Y, et al. Comprehensive diagnostic criteria for lgG4related disease (IgG4-RD), 2011. Mod Rheumatol 2012;22:21-30.

7 Kamisawa T, Anjiki H, Egawa N, et al. Allergic manifestations in autoimmune pancreatitis. Eur J Gastroenterol Hepatol 2009;21:1136-9.

8 Yao Q, Wu G, Hoschar A. Igg4-Related Mikulicz's disease is a multiorgan lymphoproliferative disease distinct from Sjögren's syndrome: a Caucasian patient and literature review. Clin Exp Rheumatol 2013;31:289-94.

9 Mulholland GB, Jeffery CC, Satija P, et al. Immunoglobulin G4-related diseases in the head and neck: a systematic review. J Otolaryngol Head Neck Surg 2015:44:24.

10 Chaudhry IA. Igg4-Related orbitopathy. Middle East Afr J Ophthalmol 2015;22:405-6

11 Andrew NH, Sladden N, Kearney DJ, et al. An analysis of IgG4-related disease (IgG4-RD) among idiopathic orbital inflammations and benign lymphoid hyperplasias using two consensus-based diagnostic criteria for IgG4-RD. Br J Ophthalmol 2015;99:376-81.

12 Lokdarshi G, Pushker N, Bajaj MS. Sclerosing lesions of the orbit: a review. Middle East Afr J Ophthalmol 2015;22:447-51.

13 Sato Y, Ohshima K-ichi, Ichimura K, et al. Ocular adnexal IgG4-related disease has uniform clinicopathology. Pathol Int 2008;58:465-70.

14 Khosroshahi A, Wallace ZS, Crowe JL, et al. International consensus guidance statement on the management and treatment of lgG4-related disease. Arthritis Rheumatol 2015;67:1688-99.

15 Thompson A, Whyte A. Imaging of IgG4-related disease of the head and neck. Clin Radiol 2018;73:106-20

16 Deshpande V, Gupta R, Sainani N, et al. Subclassification of autoimmune pancreatitis: a histologic classification with clinical significance. Am J Surg Pathol 2011;35:26-35.

Copyright 2020 BMJ Publishing Group. All rights reserved. For permission to reuse any of this content visit

https://www.bmj.com/company/products-services/rights-and-licensing/permissions/

BMJ Case Report Fellows may re-use this article for personal use and teaching without any further permission.

Become a Fellow of BMJ Case Reports today and you can:

Submit as many cases as you like

- Enjoy fast sympathetic peer review and rapid publication of accepted articles

Access all the published articles

Re-use any of the published material for personal use and teaching without further permission

Customer Service

If you have any further queries about your subscription, please contact our customer services team on +44 (0) 2071111105 or via email at support@bmj.com.

Visit casereports.bmj.com for more articles like this and to become a Fellow 